\title{
A Review of the Linkages between Emotional Intelligence and Leadership in the Military Forces
}

\author{
Sonia Aguilar
}

$\mathrm{PhD}$, Assistant Professor of Management, Fort Hays State University, USA

\section{Babu George}

PhD, Associate Professor of Management, Fort Hays State University, USA

\begin{abstract}
This paper summarizes the arguments and counterarguments within the scientific discussion on the issue of emotional intelligence (EI) in the military leadership. Extant literature indicates the possibility that emotional intelligence improves leadership capabilities and ethical conduct of military leaders. However, military leadership has historically been averse to leveraging EI, primarily due to concerns about a potential weakening in task orientation that it would cause. The neglect to nurture EI results in adaptability issues when military leaders try to engage in social relationships in their roles as members of the civil society. It is possible that tapping into EI can help our Veterans gain resiliency against posttraumatic stress, relationship dysfunction, sexual issues, attachment disorders, among other issues. Helping veterans re-integrate into civilian life should be a priority and is an ethical necessity. Investigation in the paper is carried out in the following logical sequence: identification of the scope of study, based on the generic literature on leadership and EI; defining specific issues and associated problem statements, primarily based on surveying gaps in the literature on military leadership; proposition of solutions, based on theories and models in the literature. The views presented here gains additional currency, given the fact that the presence of armed forces in non-combat peacekeeping missions globally suddenly has recently increased. Also, while this research highlights problems specific to the US military forces, we believe its findings have global applicability.
\end{abstract}

Keywords: emotional intelligence, military, veterans, task orientation, PTSD, relationships, leadership, ethics, resiliency, service members.

JEL Classification: M12, M54, I38.

Cite as: Aguilar, S., George, B. (2019). A Review of the Linkages between Emotional Intelligence and Leadership in the Military Forces. Business Ethics and Leadership, 3(2), 29-38. http://doi.org/10.21272/bel.3(2).29-38.2019.

(C) The Authors, 2019. This article is published with open access at Sumy State University.

\section{Introduction}

Emotional intelligence is crucial in maintaining personal relationships, providing ways to address conflict, ensure mutual emotional satisfaction, and promote overall well-being (Batool \& Khalid, 2012; Eslami, Hasanzadeh, \& Jamshidi, 2014; Malouff, Schutte, \& Thorsteinsson, 2014). It is also widely recognized that emotional intelligence is extremely important in developing leadership within the business realm, including creating a shared vision, building relationships, and inducing superior job performance (Boyatzis \& Soler, 2012; George, 2000; Shahhosseini, Silong, \& Ismaill, 2013).

Emotional intelligence in the military forces is a timely but relatively underexplored topic. Military leaders today engage with an utterly new array of cultural, intellectual, and practical challenges that did not even exist ten years ago, all requiring high emotional intelligence. Conventional leadership in the Military has typically included the execution of the mission and supporting one's unit but not the emotional wellbeing of its members. For instance, combat veterans have faced significant challenges with personal relationships, including PTS, intimate partner violence, sexual dysfunction, and attachment disorders (Kar \& O'Leary, 2013; Pinsky, 2016; Turner \& Chessor, 2015). This directly suggests a likelihood that veterans need to be nurtured in emotional intelligence.

Researchers have called for studies that evaluate the effects of emotional intelligence on Veterans' thoughts and behaviors (Bond, 2016; Paradiso, Beadle, Raymont, \& Grafman, 2016), as well as the impact on military leadership (Kark, Karazi-Presler, and Tubi, 2016). These studies highlight the need for further research to investigate the impact of emotional intelligence on Military leadership. However, it is also likely that applying 
ISSN (online) - 2520-6311; ISSN (print) - 2520-6761

emotional intelligence in a Military leadership context poses considerable challenges, including task-related behavior versus relationship-focused behavior, conflict management styles among military leadership, flexibility and creativity versus conformity and discipline, and the gap between civilian leadership and military leadership as it applies to emotional intelligence (Baker, 2012; Kark, Karazi-Presler, and Tubi, 2016; Livingstone et al., 2002; Singh, 2014). Given this, an interesting problem worthy of investigation is the disparity between the need for emotional intelligence and the demands of Military leadership.

There is an important ethical side to the emotional intelligence debate. Sustaining a work environment that boosts emotional intelligence is needed for the health of the workforce (Holian, 2006). Emotional intelligence could increase the probability of ethical behavior, observe Deshpande and Joseph (2009). Emotional intelligence could help us guess the ethical intentions of others - which a valuable knowledge for the military personnel is, gained in an intuitive process. Emotional intelligence could increase the level of tacit knowledge shared by a community of people, which increases its social capital, too (George, 2007). Tacit shared understanding will particularly help with the deployment and coordinated movement of the forces.

The purpose of this paper is to explore the problem of emotional intelligence in the Military, with special reference to (i) how Veterans' level of emotional intelligence affects their overall organizational performance, and (ii) how this relates to Military leadership skills in general. We hope our analysis will offer insights on balancing the challenges that members of the Military face. This includes challenges that happen within the Military - specifically leadership - as well as challenges that occur when Military Service members return to civilian employment - specifically organizational behaviors. Overall, relevant ethical issues are integrated into the discussion, even as the primary focal point of this paper is emotional intelligence.

\section{What is Emotional Intelligence?}

The original Mayer-Salovey model of emotional intelligence is a pioneering effort at framing emotional intelligence (Salovey \& Mayer, 1990). Emotional intelligence, according to this framework, is understood as the ability to examine one's own feelings in addition to other people's feelings, to separate and classify those emotions, and to use that understanding as a way to both reflect and behave. Mayer et al. (2004) classify emotional intelligence through four branches of emotional skills or behaviors: 1) perception of emotions, 2) use of emotion to facilitate thought, 3) understanding and analyzing of emotion, and 4) the management of emotion.

These four domains build on and off one another. This theory is an appropriate lens through which to investigate how the emotional intelligence of Military Service members affects their personal relationships and leadership competencies as it offers a nuanced and comprehensive way to evaluate emotional intelligence. Such frameworks have been used by scholars in a variety of academic fields looking at emotional intelligence (Elias \& George, 2012; Parke, Seo \& Sherf, 2015; Rouhani, 2013).

The perception of emotions is the first branch of the Mayer-Salovey model, which includes basic capacities to recognize and articulate emotions in one's own life and in one's own state of being, like happiness or sadness, as well as the perception of emotions that are a function of both body language and facial expressions (Mayer et al., 2004). Emotional perception implies consciousness of emotions in everyday life and culture, where an individual can recognize and classify rudimentary emotions in expressions, songs, or even narratives (Mayer, Caruso, \& Salovey, 2000). The second branch is the role of emotion to facilitate thought. In this branch, emotion is utilized to steer reasoning and thinking, including deciphering emotions and using these feelings to make decisions (Mayer et al., 2004). Emotional facilitation encompasses the absorption and subsequent integration of basic emotions by considering one next to the other, in addition to another sentiment, aiding in the prioritization of thought and contribution to decision-making and memory (Mayer et al., 2000). Understanding emotions is the third branch, which comprises the ability to analyze emotion, and includes the ability to comprehend and evaluate complex emotions, emotional amalgams, emotional perspectives, and emotional transitions, as well as recognizing the relationships between emotions (Mayer et al., 2004). The fourth branch is the management of emotion, which includes the ability to control emotions within the framework of the individual's objectives and experiences (Mayer et al., 2004). Within this branch, the individual has the ability to deal with personal emotions, regulating through reflection thus, fostering emotional growth (Mayer et al., 2000).

Emotional intelligence has a significant positive impact on the psychological well-being of employees (Ahmadi, Azar, Sarchoghaei, and Nagahi, 2014). Chen, Peng, and Fang (2016) tested whether emotional intelligence would mediate the relationship between age and Subjective Well-Being (SWB) and their 
mediation model was supported: emotional intelligence partially mediated the relationship between age and life satisfaction, and fully mediated the relationship between age and affective well-being. Their findings suggested that older adults may use their increased emotional intelligence to enhance their SWB.

The investigation by Johnson and Blanchard (2016) highlighted the pathways through which mood perception affects perceived stress and symptom reporting among undergraduate students; more specifically it looked at depression, anxiety, positive affect, and negative affect as mediators between a) emotional intelligence (EI) and b) perceived stress and symptom reporting. Results indicated that on the EI measure used in this study, the Trait Meta-Mood Scale (TMMS) subscales, attention was not related to perceived stress or symptom reporting. Mood repair and clarity were significantly and inversely related to perceived stress and symptom reporting. Anxiety and depression were the primary mediators in these relationships.

Understanding how emotional intelligence affects the psychological well-being may help Military Service members returning from combat duty to overcome some of the challenges they face reintegrating into civilian life. Particularly, the application of EI could facilitate the transition from a Military work setting to a civilian work setting. Further research may fuel the interest of educational institutions, human resource managers, and the military to develop programs that focus on increasing emotional intelligence in an effort to improve personal well-being and leadership proficiencies of veterans and service members.

\section{Emotional Intelligence in Personal - Romantic Relationships}

In order to understand the broad scope of influence of emotional intelligence, it is important to understand how personal relationships revolve around its judicious application. Batool and Khalid (2012) investigated the possibility that emotional intelligence could help predict the quality of marriage for couples in Pakistani. The authors used 85 couples, ranging in age from 21 to 40 years and marriage length of 3 to 10 years. Using the Scale of Emotional Intelligence, Marital Adjustment Questionnaire, and Conflict Resolution Questionnaire, the authors' results indicated that there was a significant positive relationship between emotional intelligence and indicators of marital quality, particularly through the lenses of marital adjustment and conflict resolution. Batool and Khalid also found that interpersonal skill, empathy, optimism, and impulse control, as dimensions of emotional intelligence, were prominent predictors of marital quality.

Eslami, Hasanzadeh, and Jamshidi (2014) found that there was a significant and positive relation between emotional intelligence and marital satisfaction. The results of their linear regression also showed that the general emotional intelligence predicts the quality of marital satisfaction. The association between the emotional intelligence of an individual and his or her self-reported romantic relationship satisfaction is significant, as was the relationship between an individual's emotional intelligence and the partner's level of satisfaction with the relationship (Malouff, Schutte, and Thorsteinsson, 2014).

The study by Zeidner and Kloda (2013) tested for actor and partner effects in the relationship between abilitybased EI and adaptive marital relationships and satisfaction employing a standard dyadic design involving 100 young heterosexual couples. Participants were assessed on the Mayer-Salovey-Caruso Emotional Intelligence Test (MSCEIT) along with measures of conflict resolution patterns and perceived marital satisfaction. A series of path analyses provided support for actor effects - but not partner effects - in the association of EI, assessed as ability, and marital variables. Overall, the data provide only partial support for the common claim and some prior research suggesting that EI plays a pivotal role in marital relationships.

The influence of the EI dimensions is considered to be important in healthy, satisfying relationships and the ability to recognize and regulate emotions on self and others has been considered vital in marital relationships (Turner, 2015). EI dimensions are considered to be affected by the balance of individual confidence and selfawareness as well as the relationships with others and the context within which they take place. Resilience, a key component of emotional intelligence, plays an important role in well-being and may lead to a decrease of post-traumatic stress and undesirable behavior in personal relationships. A military comprehensive fitness program focused on emotional, social, and family health may help build strength and fitness in each EI dimension, increasing individual, family, and Army resilience and possibly the quality of their personal relationships.

\section{Emotional Intelligence in Business Leadership}

A central movement in the leadership development literature is the increasing need to improve social and interpersonal skills in executives. Organizations benefit from executive development programs tailored to the specific needs of participants. They also benefit from developing opportunities for those that may have 
ISSN (online) - 2520-6311; ISSN (print) - 2520-6761

underdeveloped skills. Researchers have discovered that emotional intelligence is extremely important in developing leadership within the business realm, including creating a shared vision, building relationships, and inducing superior job performance (Boyatzis \& Soler, 2012; George, 2000; Shahhosseini, Silong, \& Ismaill, 2013).

Boyatzis and Soler (2012) illustrated the role of emotional and social intelligence in family business leaders and how it can lead to a shared vision and dramatic increase in the success of a family business. The authors' results indicated that using emotional and social intelligence, family business members inspired others by building resonant relationships with them, particularly by creating a shared vision among the various stakeholders in the family, the organization and the community. They got others excited about the vision using positive, emotional contagion. The contagion and resonance spread to others in the family, organization, and region.

Feelings play a central role in the leadership process. More specifically, emotional intelligence contributes to effective leadership in organizations. Four major aspects of emotional intelligence include: the appraisal and expression of emotion, the use of emotion to enhance cognitive processes and decision making, knowledge about emotions, and management of emotions (George, 2000). George, also proposes how emotional intelligence contributes to effective leadership by focusing on five essential elements of leader effectiveness: development of collective goals and objectives; instilling in others an appreciation of the importance of work activities; generating and maintaining enthusiasm, confidence, optimism, cooperation, and trust; encouraging flexibility in decision making and change; and establishing and maintaining a meaningful identity for an organization. Shahhosseini, Silong, and Ismaill (2013) however point out that, despite the intense interest of the media and business consultants in the field of emotional intelligence (EI) and its increasingly popular use in organizations, there is little empirical evidence to support these claims.

Emotional intelligence has been considered to be a valid concept that plays an important role in the workplace (Goleman, 2011). In a survey completed by veterans, with post-traumatic stress (PTS), results showed that personal motivation, self-efficacy, work skills, interpersonal issues, health, and cognitive problems rated as most impactful on work (Boyatzis et al., 2012). Studies also support that emotional intelligence is linked to indices of leadership style and effectiveness (George, 2000). Vocational rehabilitation and employment programs have been established with the intent to assist Veterans with certain service-connected disabilities to obtain stable and suitable employment. Mandatory programs such as TAPs (Transition Assistance Programs) were put in place to assist exiting service members to transition from a military setting to a civilian work setting. Despite its good intentions, TAPs failed to prepare service members for the workforce (Morgan, 2017).

It is also widely assumed that emotional intelligence will increase as work experience increases. Nonetheless, there is limited research that has examined the relationship between emotional intelligence and work experience of veterans. Future investigations would need to examine the degree of influence EI plays on employment outcomes and its impact on leadership proficiencies of Veterans in the work environment.

\section{Emotional Intelligence in the Military Leadership}

The issue of conflict management styles among Military leadership and team members is a major concern, particularly given the external changes in the nation's security environment and technological advancements. Baker (2012) studied the relationship between emotional intelligence and conflict resolution among leaders in the National Guard and found a positive association. The challenges and tensions that characterize leadership in the military context have been analyzed by Kark, Karazi-Presler, and Tubi (2016). Their objective was to scrutinize the paradoxes in this unique setting while exploring the challenges, opportunities, and advantages posed by these paradoxes for leadership. This research identifies different types of paradoxes, among them: (a) shared leadership versus hierarchical leadership, (b) flexibility and creativity versus conformity and discipline, (c) complexity and chaos versus simplicity and linearity, (d) hegemonic and prototypical leadership versus leadership of multiple identities, and last (e) distant leadership and exchange relationship versus intimate leadership and communal relationship.

Singh observed that the Indian Armed Forces have been a patriotic force with a well-deserved reputation for bravery and professionalism, but this reputation suffers when its personnel, particularly the leaders, become wayward and break the rules of fair conduct (Singh, 2014). Singh measured the level of emotional intelligence of the Officers of the Indian Armed Forces to discover whether there is a difference in the level of emotional intelligence of the Officers of the Army, Navy and the Air Force. Singh also sought to establish whether the senior officers of the Indian Armed Forces have higher levels of emotional intelligence compared to the junior officers and to find whether there was a difference between the level of emotional intelligence of male and 
female officers. His results indicated that $9.5 \%$ of Officers are in Exceptional category and $33.4 \%$ in High category of emotional intelligence.

Numerous researchers have noted the need for further research to investigate the impact of emotional intelligence on Military leadership (Kark, Karazi-Presler, and Tubi, 2016; Singh, 2014), as well as its impact on veterans' feelings and actions (Bond, 2016; Paradiso, Beadle, Raymont, \& Grafman, 2016). Applying emotional intelligence in a Military context may help address some of the challenges that Veterans face and may contribute to effective Military leadership.

Despite the increased interest in defining and measuring emotional intelligence, many questions remain unanswered and must be considered before utilizing emotional intelligence in a Military context or for Military training, recruitment, or selection purposes. Empirically based examination and ability-based emotional intelligence measures in relation to effective leadership behaviors in a military context would be necessary. Assessment instruments such as the Bar-On's Emotional Quotient inventory (EQ-i) may help in measuring individual levels of emotional intelligence and in providing assessment reports and program development recommendations to improve EI scores. Livingstone, Nadjiwon-Foster, and Smithers (2002). The Bar-on model includes intrapersonal and interpersonal realms that directly affect emotional and social fitness. The intrapersonal realm addresses the inner self while the interpersonal realm focuses on the areas that the Military Service members need to attain strength in order to have effective relationships. These areas include empathy, social responsibility and interpersonal relationships (Bar-On, 1997). According to Dr. Reuven Bar-On, emotional intelligence addresses the emotional, personal, social and survival aspects of intelligence. These aspects are often more important for daily functioning than the more traditional aspects of intelligence, and while there is not much that can be done to improve cognitive IQ, there is much that can be done to improve emotional intelligence specifically in the context of Military leadership.

\section{Emotional Intelligence and the Veterans}

In Military contexts, the fifteen facets of Trait Emotional Intelligence overlap considerably with the Leader Attributes and Competencies established by doctrine used to evaluate Officer performance. Bond (2016) looked at Trait Emotional Intelligence, which he argued is a well-established predictor of desirable workplace outcomes such as job performance. Research by Handley (2015) focuses competencies displayed by members of the modern Military and identifies how these assist the transition to the private security sector. Rather than discussing obvious skills such as weaponry know-how or military police investigative knowledge, by means of a literature review, the research examined the transfer of military leadership skills, the value of military ethics and ethos and military adaptability and mental robustness in the private security sector. The Military takes leadership training very seriously with a variety of training required to progress through the ranks and the author identified how Military Leadership transitions into the private security sector, both during times of increased pressure and in routine encounters.

Paradiso et al. (2016) used a sample of 185 combat veterans from the W.F. Caveness Vietnam Heady Injury Study who at the time of assessment did or did not have suicidal thoughts, as gauged by the Beck Depression Inventory. Those participants were then gauged using the MSCEIT test, looking at two components: emotional processing and emotional perceptions. Their results indicated that those veterans who endorsed suicidal thoughts had poorer emotional processing; however, emotion perception did not have a significant effect. Moreover, Veterans who had suicidal thoughts had lower education, were deployed at a younger age, and had more negative social interactions post-deployment.

Combat Veterans have faced significant challenges with personal relationships, including PTSD, intimate partner violence, sexual dysfunction, and attachment disorders according to research (Kar \& O'Leary, 2013; Pinsky, 2016; Turner \& Chessor, 2015). Military personnel and veterans are considered to have elevated rates of medical and psychiatric conditions, including anxiety and mood disorders.

Despite the presence of these findings, training initiatives to develop emotional intelligence in service members are limited or absent in institutional training programs. Emotional intelligence involves understanding oneself and others, relating to people, and adapting to and coping with immediate surroundings in order to be successful in dealing with environmental demands (Bar-On, 1997). Thus, it is important that training is developed that focuses on interpersonal and social competencies. If implemented effectively, these competencies can lead to successful interaction with the Military Service members' family, neighbors, coworkers and other members in their life. 


\section{Brain Injuries and Veterans' Emotional Intelligence}

Sub-facets of experiential and strategic EI can be characterized as separable but related processes that depend upon a core network of brain structures within the frontal, temporal and parietal cortex. Findings from a study investigating the neural bases of these specific components for EI in a sample of 130 combat Veterans with penetrating traumatic brain injury showed the neural mechanisms underlying experiential (perceiving and using emotional information) and strategic (understanding and managing emotions) facets of EI. The results indicated that two facets of EI (perceiving and managing emotions) engage common and distinctive neural systems, with shared dependence on the social knowledge network, and selective engagement of the orbitofrontal and parietal cortex for strategic aspects of emotional information processing (Operskalski et al., 2015).

Driscoll et al. (2012) used a sample of 192 male Vietnam combat Veterans who had sustained focal penetrating traumatic brain injuries, and 54 non-brain-injured Veterans to investigate how lesions, as well as different brain regions, effects emotional empathy. Using the Balanced Emotional Empathy Scale, the authors discovered that damage in several brain regions, particularly the ventrolateral prefrontal cortex, left and right posterior temporal lobes, and insula, was associated with diminished emotional empathy. These findings provided insight into the neural substrates of emotional empathy and reinforced the notion that emotional empathy is supported by a distributed network of brain regions. Moreover, their findings point to neurological damage combat veterans may have sustained, and how that effects their capacity for emotional empathy.

Competencies underlying emotional intelligence have clear neural foundations and can be impaired despite otherwise normal basic intellectual functioning. Emotional Intelligence permits the evaluation of individual differences in emotional and social processes (Krueger, 2009). These processes are key factors in making the right versus wrong decisions in a veteran's life. Further research will need to examine differences in emotional intelligence processes and neurological impact for veterans.

\section{Veterans' Emotional Wellbeing in PTS Situations}

Boden et al. (2012) examined how emotional clarity and a specific emotion regulation strategy, cognitive reappraisal, interact to predict Posttraumatic Stress Disorder (PTSD) symptom severity and positive affect among treatment-seeking military Veterans ( $\mathrm{N}=75,93 \%$ male) diagnosed with PTSD. The authors found that the combination of high levels of emotional clarity and frequent use of cognitive reappraisal were associated with (a) lesser total PTS severity after accounting for shared variance with positive affect and the extent to which emotions are attended to (attention to emotions), and (b) greater positive effect after accounting for shared variance with total PTS severity and attention to emotions.

Social support could mediate in the relationship between emotional intelligence and PTSD symptoms (Hofman et al., 2016). Emotional intelligence is significantly associated with PTSD symptoms and social support may play an integral role in the relationship between emotional intelligence and PTSD (Gaher et al., 2014). Gaher tried to understand the functional mechanisms between PTSD and alcohol use and problems. Specifically, the role of negative urgency and emotional intelligence were investigated as vulnerability and resiliency factors, respectively. This study utilized experience sampling to test associations between PTS symptoms and alcohol use and related problems in a sample of $90 \mathrm{OIF} / \mathrm{OEF}$ Veterans. Elevations in PTS symptoms during the day were associated with subsequent increases in alcohol use and associated problems that night. PTS symptoms were associated with greater problems above and beyond the effect of drinking level at both the within- and between-person level. Emotional intelligence was associated with lower negative urgency, fewer PTS symptoms, and less alcohol use and associated problems. The effects of emotional intelligence were primarily indirect via negative urgency and the effects of negative urgency on alcohol use and problems were indirect via its positive association with PTS symptoms. Hypothesized cross-level effects of emotional intelligence and negative urgency were not supported. The findings suggest a functional association between PTS symptoms and alcohol consumption. The association between PTS symptoms and alcohol consumption is consistent with a self-medication model. However, the significant associations between PTS symptoms and alcohol problems, after controlling for use level, suggest a broader role of dysregulation.

Posttraumatic stress has been known to be a chronic condition that afflicts combat veterans and civilians. Yet, the relationship between PTS and functional quality of life remains to be completely understood. National Vietnam Readjustment Study revealed that higher levels of war zone stress exposure and greater PTS symptom levels were shown to be generally associated with significantly more lifetime readjustment problems (Kulka, 1990).

Data analysis of emotional intelligence may help in dealing with the stressors of the environment, and with the ability to understand their emotions as well as the emotions of others. In many instances, PTS may be 
Business Ethics and Leadership, Volume 3, Issue 2, 2019

ISSN (online) - 2520-6311; ISSN (print) - 2520-6761

contributing to a lower quality of life. It may be an area of study that researchers and health institutions may need to consider to further examine the functioning impairments of PTS in veterans.

\section{Emotional Intelligence and Relationship Challenges in the Veterans}

Developing a program to apply the emotional intelligence competencies to the lives of Veterans may increase their comprehensive mental fitness and resiliency. The program can be established by utilizing emotional intelligence assessment instruments such as the Bar-On Emotional Quotient inventory (EQ-i). The EQ-i measures the individual's level of emotional intelligence and provides an assessment report suggesting the appropriate program to develop. Education is another facet of program development. Certified counselors ordinarily aid in the understanding of the EQ-i report when utilizing the Bar-On assessment instrument. Collaboration generally takes place between the certified counselor and the individual with the goal of developing a tailored program to improve the EI scores.

In a study, 177 couples presenting for couple therapy at two Veteran Administration Medical Centers completed assessments of relationship satisfaction prior to therapy and weekly during therapy. Results revealed that the average couple showed significant gains in relationship satisfaction during treatment; gains were larger for couples beginning therapy in the distressed range than for couples in the no distressed range. Rates of premature termination were high, with $19 \%$ of couples completing fewer than three sessions and $62 \%$ rated as not completing a "full course" of therapy. Benchmarking analyses demonstrated that the average gains were larger than would be expected from natural remission and similar to previous effectiveness trials; however, average gains were smaller than those observed in couple therapy efficacy trials. Relationship, psychological, and demographic characteristics were generally unrelated to the amount of change in therapy after controlling for initial satisfaction. However, African American couples showed significantly larger gains than Caucasian, non-Hispanic couples. Thus, though yielding smaller effects than those shown in efficacy trials, the impact of couple therapy for veterans' relationship problems appears to generalize across various demographic, psychological, and relationship characteristics (Doss et al., 2012).

The link between PTS and physical Intimate Partner Violence (IPV) in Operational Enduring Freedom/Operation Iraqi Freedom/Operation New Dawn (OEF/OIF/OND) was examined in Veterans. Using a sample of 110 male participants recruited from the Northport Veterans Affairs Medical Center (VAMC), the authors compared three separate models to determine which best explained the relationships between PTS, IPV, emotional intimacy, and relationship satisfaction. Their results indicated that $33 \%$ of Veterans had clinically elevated PTS scores, and $31 \%$ of the men reported that they engaged in physical IPV in the past year, and that poor emotional intimacy mediated the association between PTS symptoms and perpetration of physical IPV. Moreover, they found that past pre-deployment IPV perpetration was shown to be a predictor for current post-deployment physical IPV perpetration (Kar and O’Leary, 2013).

The romantic relationships of reservists following a year after wartime deployment were examined. The authors found four themes: (a) intermittent idealized closeness, (b) transition from independence to interdependence, (c) transition in the primary source of social support, and (d) ongoing renegotiation of roles (Karakurt et al., 2013). More specifically, the authors found that intermittent idealized closeness fluctuated over time and was an individual rather than a joint phenomenon, and that couples had to relearn how to be interdependent, and for some this was the most difficult aspect of reunion. In addition, individuals shifted away from partners for social support during deployment and gradually shifted back to relying on partners following reunion. Transitions in work and family roles were negotiated on an ongoing basis throughout the year.

Issues faced by combat veterans in committed relationships were examined to analyze the correlations between PTS symptoms, attachment quality, sexual satisfaction, and sexual functioning in romantic relationships. The results indicated that PTS symptoms from combat veterans are correlated with attachment quality, sexual satisfaction, and sexual functioning in romantic relationships. Turner and Chessor (2015) investigated whether the romantic partners of Veterans suffered higher levels of psychological distress and destructive relationship conflict. These authors also gauged the relationship satisfaction and perceived social support those romantic partners received, comparing those results with 87 civilian partners. Their results indicated that Australian females who were romantically involved with Veterans from the Afghanistan war were more vulnerable to experiencing relationship dysfunction. Moreover, those women are at an increased risk for impaired psychological health, as compared to the general Australian population (Pinsky, 2016).

Leaders who are able to regulate their own emotions in order to attend the needs of their followers may be viewed as more effective (George, 2000). Veterans with emotional intelligence may be able to maintain 
ISSN (online) - 2520-6311; ISSN (print) - 2520-6761

positive relationships with others, particularly in a relationship-centered setting. They may be able to attain higher levels of stress tolerance and have the ability of not losing control of their emotions during difficult times. In addition, Veterans with emotional intelligence may also be able to withstand adversity without a physical or mental breakdown. Emotional intelligence may help veterans deal with the stress and uncertainty of transitioning from a military setting to a civilian work setting and establish effective relationships with family, neighbors, and co-workers.

\section{Conclusion}

Emotional intelligence is important in developing leadership within the business realm, including creating a shared vision, building relationships, and inducing superior job performance (Boyatzis \& Soler, 2012; George, 2000; Shahhosseini, Silong, \& Ismaill, 2013). EI is a vital manifestation of the psychological capital held by an individual. Psychological Capital directly leads to positive organizational outcomes including metrics such as lower employee absenteeism, lower employee cynicisms and intentions to quit, higher job satisfaction and commitment, and higher organizational citizenship behaviors.

Literature shows that there is a significant positive relationship between emotional intelligence and the quality of relationships, particularly within the areas of conflict resolution and relationship satisfaction (Batool \& Khalid, 2012; Eslami, Hasanzadeh, \& Jamshidi, 2014). Applying the concept of emotional intelligence may help address challenges when transitioning from a military to civilian work environment. Our veterans face numerous relationship barriers and problems, including posttraumatic stress and relationship dysfunction, sexual issues, attachment disorder, with accompanying psychological impairment (Kar \& O'Leary, 2013; Pinsky, 2016; Turner \& Chessor, 2015) and emotional intelligence can help them cope better with their tragedies and bring in renewed hopes. Also, by understanding and identifying how emotional intelligence affects relationships and leadership proficiencies, Military Service members will be able to overcome the challenges they face re-integrating into civilian work life.

The present paper consolidates the literature that investigates the impact of emotional intelligence on Military leadership and brings home a set of unified arguments in favor of the application of emotional intelligence related concepts in military affairs (Kark, Karazi-Presler, and Tubi, 2016; Singh, 2014; Bond, 2016; Paradiso, Beadle, Raymont, \& Grafman, 2016). Only by recognizing how emotional intelligence impacts the possibly conflicting demands of Military leadership and personal relationships, the Military will be able to develop and strengthen training programs in both areas, helping Military Service Members maximize their potential both within and outside of the Military.

Historically, the prevalent thought in the military ranks has been that emotions may interfere with effective behaviors - it is high time for this to change, especially in noncombat situations. An important first step in this regard is to recognize that emotional intelligence within a specifically Military leadership setting presents different challenges than the civilian employment and then build a framework for emotional intelligence leadership to be infused in the military. Emotional intelligence leadership infusion may allow for higher levels of resiliency. Resiliency is a form of mental fitness that allows for a quick recovery from setbacks, failure or adversity. It is considered to be a key component of emotional intelligence that is malleable and trainable. Resiliency helps leaders carry out difficult missions even in the face of adversity.

According to Chief of Staff of the US Army General George W. Casey (2009), the key to increased resiliency is to place the same level of enthusiasm toward conditioning the mind as it is placed towards conditioning the body. Veterans and service members deal with the realities of war and the realities of civil life. Therefore, the need to bring mental fitness to the same level of attention as physical fitness is imperative. It is necessary to examine emotional intelligence measures relative to leadership behaviors in a military setting. Determining whether emotional intelligence is conducive to successful leadership in a Military context, will enable researchers to gain greater understanding of the emotional intelligence components useful to develop in a program tailored to Veterans.

Despite of the lack of measuring of emotional intelligence, the Army has begun to integrate resilience training in all of its officers' Military education courses. As a key component of emotional intelligence, resilience may help veterans withstand adversity and have a better understanding of the benefits it brings to their military and personal lives. Yet, many questions remain unanswered and must be considered before emotional intelligence should be used for military training purposes. Future studies should examine the impact of emotional intelligence in a military context and whether it provides an increase to their quality of life that may also lead to an effective and prosperous military work to civilian work transition. 
Business Ethics and Leadership, Volume 3, Issue 2, 2019

ISSN (online) - 2520-6311; ISSN (print) - 2520-6761

Note: A preliminary version of this work has been presented at the Midwest Academy of Management 2018 conference, held at St. Louis, MO, USA, and included in the proceedings.

\section{References}

1. Baker, W. L. (2012). Emotional intelligence and conflict resolution styles: Implications for United States National Guard leaders (Doctoral dissertation, Capella University).

2. Batool, S. S., \& Khalid, R. (2012). Emotional intelligence: A predictor of marital quality in Pakistani couples. Pakistan Journal of Psychological Research, 27(1), 65.

3. Bond, A. L. (2016). Trait Emotional Intelligence Differences in Pre-Career and Mid-Career United States Military Leaders (Doctoral dissertation, Auburn University).

4. Boyatzis, R. E., \& Soler, C. (2012). Vision, leadership and emotional intelligence transforming family business. Journal of Family Business Management, 2(1), 23-30.

5. Deshpande, S. P., \& Joseph, J. (2009). Impact of emotional intelligence, ethical climate, and behavior of peers on ethical behavior of nurses. Journal of Business Ethics, 85(3), 403-415.

6. Driscoll, D. M., Dal Monte, O., Solomon, J., Krueger, F., \& Grafman, J. (2012). Empathic deficits in combat veterans with traumatic brain injury: a voxel-based lesion-symptom mapping study. Cognitive and behavioral neurology, 25(4), 160-166.

7. Eslami, A. A., Hasanzadeh, A., \& Jamshidi, F. (2014). The relationship between emotional intelligence health and marital satisfaction: A comparative study. Journal of education and health promotion, 3, 24-36. doi:10.4103/2277-9531.127616.

8. Fairchild, A. J., \& MacKinnon, D. P. (2009). A general model for testing mediation and moderation effects. Prevention Science, 10(2), 87-99.

9. Field Manual 6-22 Army Leadership (Washington, DC: Government Printing Office, October, 2006) 5-3.

10.George, B. P. (2007). Local community's support for post-tsunami recovery efforts in an agrarian village and a tourist destination: a comparative analysis. Community Development Journal, 43(4), 444-458.

11.George, J. (2000). Emotions and leadership: The role of emotional intelligence. Human Relations, 53, 1027-1055.

12.Goleman, D. (2011). The Brain and Emotional Intelligence: New Insights, More than Sounds LLC.

13.Holian, R. (2006). Management decision making, ethical issues and "emotional" intelligence. Management Decision, 44(8), 1122-1138.

14.Kar, H. L., \& O'Leary, K. D. (2013). Emotional intimacy mediates the relationship between posttraumatic stress disorder and intimate partner violence perpetration in OEF/OIF/OND veterans. Violence and victims, 28(5), 790-803.

15.Karakurt, G., Christiansen, A. T., Wadsworth, S. M. M., \& Weiss, H. M. (2013). Romantic relationships following wartime deployment. Journal of Family Issues, 34(11), 1427-1451. doi:10.1177/0192513X12470799.

16.Kark, R., Karazi-Presler, T., \& Tubi, S. (2016). Paradox and challenges in military leadership. Leadership Lessons from Compelling Contexts (Monographs in Leadership and Management, Volume 8) Emerald Group Publishing Limited, 8, 157-187.

17.Kulka, R.A., Schlenger, W.E., Fairbank, J.A., Hough, R.L., Jordan, B.K., Marmar, C.R., Weiss, D.S. (1990). Trauma and the Vietnam War Generation: Report of Findings from the National Vietnam Veterans Readjustment Study. New York, Brunner/Mazel.

18.Livingstone, H., Nadjiwon-Foster, M., \& Smithers, S. (2002). Emotional Intelligence and Military Leadership. Canadian Forces Leadership Institute. Canada: Toronto.

19.Malouff, J. M., Schutte, N. S., \& Thorsteinsson, E. B. (2014). Trait emotional intelligence and romantic relationship satisfaction: A meta-analysis. The American Journal of Family Therapy, 42(1), 53-66. Doi:10.1080/01926187.2012.748549.

20.Mayer, J. D., Salovey, P., \& Caruso, D. R. (2004). Emotional intelligence: Theory, findings, and implications. Psychological inquiry, 15(3), 197-215.

21.Morgan, Angie. (2017). Armed Forces Transition Program fails to prepare veterans for work. News Week, U.S. Edition. http://www.newsweek.com/armed-forces-transition-program-fails-prepare-veterans-civilianwork-705903.

22.Operskalski, J. T., Paul, E. J., Colom, R., Barbey, A. K., \& Grafman, J. (2015). Lesion mapping the fourfactor structure of emotional intelligence. Frontiers in human neuroscience, 9, 649-658. doi:10.3389/fnhum.2015.00649.

23.Paradiso, S., Beadle, J. N., Raymont, V., \& Grafman, J. (2016). Suicidal thoughts and emotion competence. Journal of clinical and experimental neuropsychology, 38(8), 1-13. doi:10.1080/13803395.2016.1172558. 
24.Parke, M. R., Seo, M. G., \& Sherf, E. N. (2015). Regulating and facilitating: The role of emotional intelligence in maintaining and using positive affect for creativity. Journal of Applied Psychology, 100(3), 917.

25.Pinsky, I.S. (2016). Attachment quality and sexual satisfaction and sexual functioning in romantic relationships for combat veterans. Theses and Dissertations-Family Sciences. Paper 43. doi:10.13023/ETD.2016.239.

26.Reuven Bar-On, Bar-O Emotional Quotient Inventory, Technical Manual (New York: Multi-Health Systems, 1997), 2.

27.Rouhani, A. (2013). An investigation into emotional intelligence, foreign language anxiety and empathy through a cognitive-affective course in an EFL context. Linguistik online, 34(2).

28.Salovey, P., \& Mayer, J. D. (1990). Emotional intelligence. Imagination, cognition and personality, 9(3), $185-211$.

29.Shahhosseini, M., Silong, A. D., \& Ismaill, I. A. (2013). Relationship between transactional, transformational leadership styles, emotional intelligence and job performance. Researchers World, 4(1), 15.

30.Singh, U. (2014). Emotional Intelligence and leadership in Indian armed forces. (Doctoral Dissertation: Osmania University).

31.Turner, J., \& Chessor, D. (2015). Relationship satisfaction, conflict and psychological distress: The impact of combat deployment to afghanistan on the romantic partners of australian army personnel. Journal of Relationships Research, 6, 12. doi:http://dx.doi.org/10.1017/jrr.2014.13. 